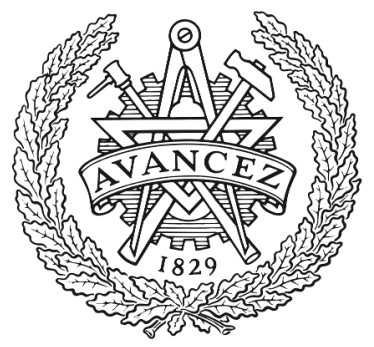

CHALMERS

UNIVERSITY OF TECHNOLOGY

\title{
Stabilities of protonated water-ammonia clusters
}

Downloaded from: https://research.chalmers.se, 2023-04-26 05:34 UTC

Citation for the original published paper (version of record):

Sundén, E., Stöchkel, K., Hvelplund, P. et al (2018). Stabilities of protonated water-ammonia clusters. Journal of Chemical Physics, 148(18). http://dx.doi.org/10.1063/1.5023620

N.B. When citing this work, cite the original published paper. 


\title{
Stabilities of protonated water-ammonia clusters
}

\author{
A. E. K. Sundén, ${ }^{1}$ K. Støchkel, ${ }^{2}$ P. Hvelplund, ${ }^{2}$ S. Brøndsted Nielsen, ${ }^{2}$ B. Dynefors, ${ }^{3}$ \\ and K. Hansen ${ }^{1,4}$ \\ ${ }^{1}$ Department of Physics, University of Gothenburg, 41296 Gothenburg, Sweden \\ ${ }^{2}$ Department of Physics and Astronomy, Aarhus University, Ny Munkegade 120, 8000 Aarhus C, Denmark \\ ${ }^{3}$ Chalmers University of Technology, 41296 Gothenburg, Sweden \\ ${ }^{4}$ Center for Joint Quantum Studies and Department of Physics, Tianjin University, Tianjin 300072, China
}

(Received 26 January 2018; accepted 16 April 2018; published online 10 May 2018)

\begin{abstract}
Branching ratios of water and ammonia evaporation have been measured for spontaneous evaporation from protonated mixed clusters $\mathrm{H}^{+}\left(\mathrm{H}_{2} \mathrm{O}\right)_{n}\left(\mathrm{NH}_{3}\right)_{m}$ in the size range $0 \leq n \leq 11$ and $0 \leq m \leq 7$. Mixed clusters evaporate water except for clusters containing six or more ammonia molecules, indicating the formation of a stable core of one ammonium ion surrounded by four ammonia molecules and a second shell consisting predominantly of water. We relate evaporative branching ratios to free energy differences between the products of competing channels and determine the free energy differences for clusters with up to seven ammonia molecules. Clusters containing up to five ammonia molecules show a very strong scaling of these free energy differences. Published by AIP Publishing. https://doi.org/10.1063/1.5023620
\end{abstract}

\section{INTRODUCTION}

Clusters containing water together with other molecules or atoms are of great interest because of their relevance to biological systems, in atmospheric processes, and as model systems for studying intermolecular hydrogen bonding. The solvation of ammonia in water is of particular interest because of ammonia's presence in the atmosphere together with water and its ability to form hydrogen bonds with water molecules. Ammonia is an important component stage of atmospheric nucleation together with water and sulphuric acid. ${ }^{1-3}$ Also amines have been shown to be strong nucleation agents together with sulphuric acid, ${ }^{4,5}$ and this field is also under active study, ${ }^{6-9}$ even addressing questions of regulatory consequences for atmospheric aerosol production. ${ }^{10}$ Effects of the charging of atmospheric components caused by the interaction with the cosmic radiation have been demonstrated, ${ }^{1-13}$ adding importance to studies of the thermodynamics of charged clusters such as those presented here. These studies are either theoretical in nature or based on measurements close to or directly in ambient conditions. For that reason alone, it is important to provide experimental benchmarks for single size-selected clusters.

Previous experiments on pure protonated water and pure protonated ammonia clusters have revealed them to be quite different in structure. Pure protonated ammonia clusters $\mathrm{H}^{+}\left(\mathrm{NH}_{3}\right)_{m}$ show shell structure and little structural isomerism in vibrational spectroscopy experiments, ${ }^{14}$ an observation that has been assigned to the weak bonding between two $\mathrm{NH}_{3}$ molecules as compared to the ammonia bond to the ammonium ion $\mathrm{NH}_{4}^{+}$. Pure water clusters $\mathrm{H}^{+}\left(\mathrm{H}_{2} \mathrm{O}\right)_{n}$, on the other hand, show a more complicated structural picture where both planar and cage-like structures have been observed. The excess proton can give rise to both Eigen and Zundel configurations, where in the first case the proton is localized on a single water molecule and in the other is shared between two molecules. Isomeric structures of both ionic configurations have been seen simultaneously in experiments. ${ }^{15}$

Of the mixed water and ammonia clusters $\mathrm{H}^{+}\left(\mathrm{H}_{2} \mathrm{O}\right)_{n}$ $\left(\mathrm{NH}_{3}\right)_{m}, m=1$ is the most studied. For $m=1$ and $n>2$, structural isomers have been identified in thermal distributions by means of infrared spectroscopy. ${ }^{16}$ High level calculations $^{16-18}$ suggest that the barrier separating these isomers can be very small. Numerous theoretical studies ${ }^{19-23}$ also suggest that the excess proton is located on the ammonia molecule lone pair. Comparing the proton affinities of $\mathrm{NH}_{3}(8.85 \mathrm{eV})$ and $\mathrm{H}_{2} \mathrm{O}(7.16 \mathrm{eV})^{24}$ is consistent with this conclusion. Even if the cluster was initially created with a $\mathrm{H}_{3} \mathrm{O}^{+}$, proton transfer to an ammonia molecule can occur with almost no barrier as shown in $a b$ initio quantum chemical calculations. ${ }^{20}$ The theoretical work also shows that the positions of the water molecules can vary, and in comparing infrared spectroscopy data with theoretical calculations, several isomers are often invoked to explain the experimental spectra. $^{22}$

Experimental studies of mixed clusters with more than one ammonia molecule are more sparse. Early studies were concerned with the temperature dependence of the rate constants for formation and evaporation of mixed clusters $\mathrm{H}^{+}\left(\mathrm{H}_{2} \mathrm{O}\right)_{n}\left(\mathrm{NH}_{3}\right)_{m}$. The clusters with $m=2-5$ and $n=1-5$ were measured in gas phase equilibrium. ${ }^{25}$ Several molecular beam mass spectrometry experiments were performed (see, e.g., Refs. 26-29) where one focal point was to find the explanation for the relatively high relative abundance of the clusters with $n=20$ and $m=1-5$. The suggested structure is a cage of water molecules surrounding a central ammonium ion, with the remaining ammonia molecules attached to the outside of the water cage. ${ }^{27}$ The subject was revisited in Ref. 30 where the same conclusion was reached. For smaller mixed clusters, the earliest proposed structure was 
four ammonia molecules surrounding an ammonium ion with water and remaining ammonia molecules attached to an outer shell. ${ }^{29}$ However, a later computational study ${ }^{30}$ suggested that this was a too simple description and that there is a competition between ammonia and water for the last two molecular positions in the inner shell and for all the spaces in the second shell.

In this paper, we report on relative stabilities of the different species in the mixed clusters $\mathrm{H}^{+}\left(\mathrm{H}_{2} \mathrm{O}\right)_{n}\left(\mathrm{NH}_{3}\right)_{m}(0 \leq n$ $\leq 11,0 \leq m \leq 7$ ) with the purpose of obtaining more information on the structural arrangements and the relative bond strengths of the molecules. The method used was spontaneous evaporation, which is arguably the most non-invasive technique for measuring the relative inter-molecular bond strengths in the clusters.

\section{EXPERIMENTAL PROCEDURE}

The experimental setup used in the experiments is essentially the same as that described in Ref. 31, and only a short description of the most important components will be given. The clusters were produced via high voltage corona discharge from an STM (scanning tunneling microscopy) needle in a mixture of gas at ambient pressure, enriched with water and ammonia. The voltage on the STM-needle was set to 3.7$4.0 \mathrm{kV}$. After creation, the clusters were introduced into a vacuum through a capillary. The capillary was heated, typically to $60^{\circ} \mathrm{C}$. The beam passed through electrostatic optics and was accelerated to $50 \mathrm{keV}$, after which it was mass selected in an electromagnet with a resolution of $m / \Delta m \approx 1000$. After the exit from the magnet, the ions flew freely for $3.37 \mathrm{~m}$ and were then analyzed with respect to translational kinetic energy with a hemispherical electrostatic analyzer. Single ion detection was accomplished with a channeltron detector (see schematic drawing in Fig. 1). Since losing a molecule lowers the kinetic energy of a cluster proportionally to the mass lost, evaporation during this free flight could be measured and the decay channel determined.
To facilitate the production of mixed ammonia and water clusters, the STM-needle was operated in an atmosphere enriched with water and ammonia, produced by bubbling atmospheric air through a beaker containing $25 \%$ ammonia dissolved in water. A fraction of the air flow bypassed this beaker, and the cluster composition was adjusted by changing this fraction. The best cluster intensities were usually obtained with most of the air flow bypassing the beaker.

\section{RESULTS}

Figure 2 shows three typical mass spectra for different air flow conditions, recorded by scanning the magnetic field. In (a), only a small portion (5\%-10\%) of the air passed through the solution before entering the chamber; in (b), the fraction was about 50\%; and in (c), all the air went through the solution. The mass range in Fig. 2 is 50-200 u which corresponds to a sum of the number of water and ammonia molecules, or rank, of $N \equiv n+m=3-11$. The indices of the cluster with highest abundance are labeled in the figure, using the convention $(n, m)$, where $n$ is the number of water molecules in the cluster and $m$ the number of ammonia molecules. The number of water and ammonia molecules in a cluster is uniquely determined by the mass below $306 \mathrm{u}$, which can be a protonated cluster with 17 water molecules or 18 ammonia molecules, i.e., up to rank 16.

Up to rank four, all three spectra are dominated by pure ammonia clusters, but for higher ranks the dominant peak in each rank contains four ammonia molecules with the remaining molecules being water. An exception occurs at rank 9 where in spectrum Fig. 2(c) the $(4,5)$ peak is slightly more abundant than the $(5,4)$ peak and another at rank 11 where the dominant peak in Fig. 2(a) only contains three ammonia molecules.

An example of a typical evaporation spectrum is shown in Fig. 3 where the cluster with mass 193 u, corresponding to the composition $\mathrm{H}^{+}\left(\mathrm{H}_{2} \mathrm{O}\right)_{5}\left(\mathrm{NH}_{3}\right)_{6}$, was selected. Lower mass peaks appear due to the metastable fragmentation that occurs

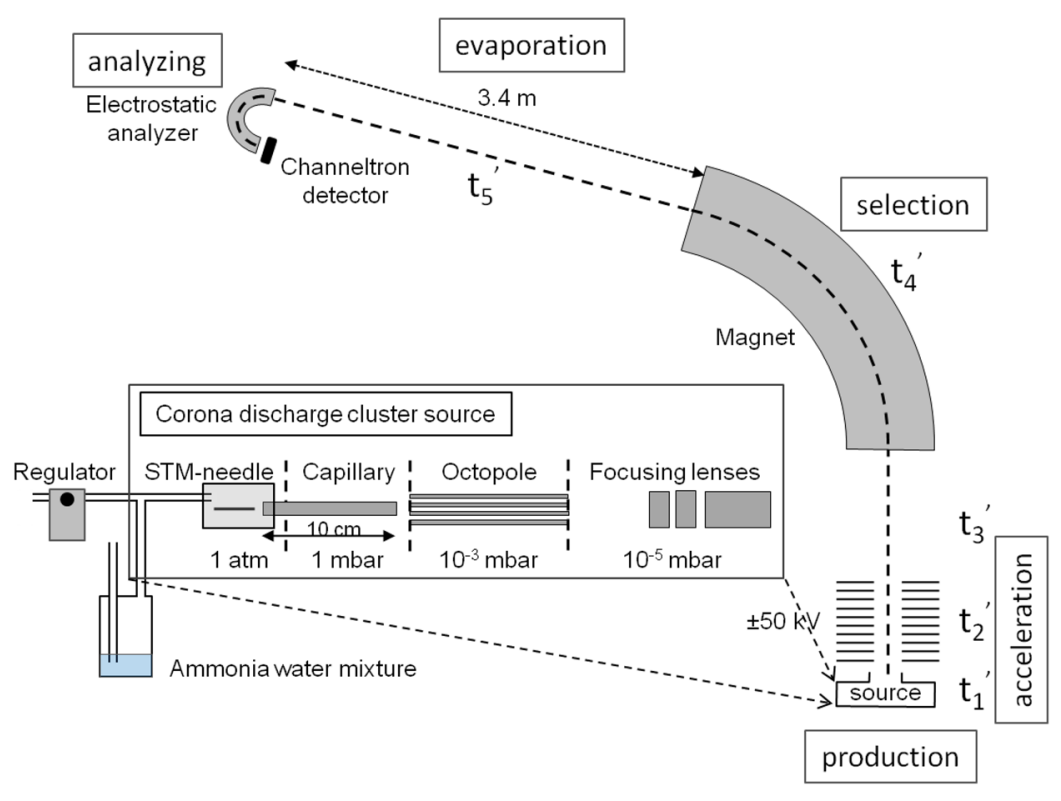

FIG. 1. Schematic drawing of the single pass accelerator used in the experiments. The source shown in the inset should be rotated $90^{\circ}$ counterclockwise and inserted at the place denoted "source" in the larger picture. In the source, atmospheric air is bubbled through a beaker with an ammonia-water mixture, and the gas is led into a small enclosure in which the STM-needle is located. 


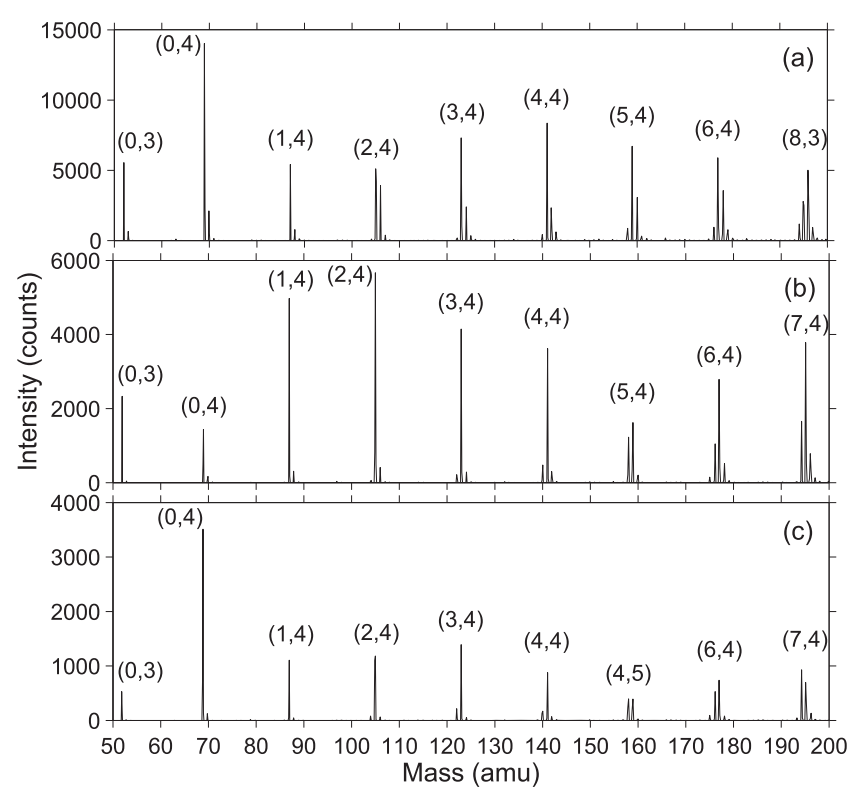

FIG. 2. Mass spectra for three different ammonia flow rates, increasing from (a) to (c). The masses 50-200 u correspond to a total number of molecules in the clusters, $N$, between 3 and 11 . The numbers $(n, m)$ represent the number of water $(n)$ and ammonia $(m)$ molecules in the cluster with the highest intensity in each group of peaks.

in the beam line after acceleration and mass selection in the magnet. The peaks are seen at masses 175 and $176 \mathrm{u}$. Multiple spontaneous evaporation is not likely in the size region measured here, ${ }^{31}$ and the intensities we see in the other daughter peaks are mostly or exclusively due to collision induced dissociation (CID) due to residual gas in the beam line. The first daughter peaks are corrected for CID in the analysis. The evaporation of dimers or larger moieties was not seen in experiments on water clusters ${ }^{32,33}$ and are not seen here either in any significant amount, although a minor contribution from such channels to the loss of several molecules can not be rigorously ruled out.

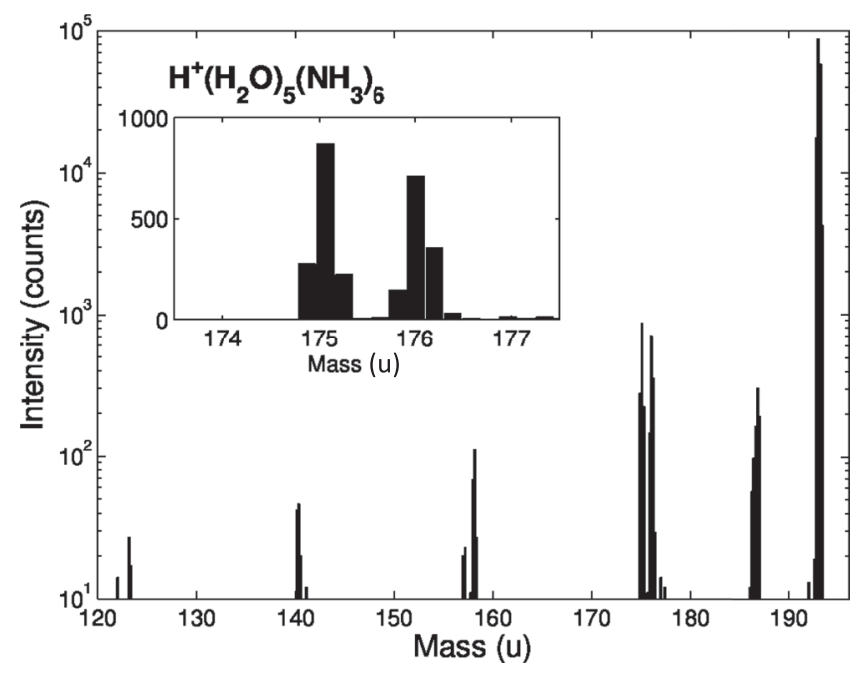

FIG. 3. Evaporation spectrum of $\mathrm{H}^{+}\left(\mathrm{H}_{2} \mathrm{O}\right)_{5}\left(\mathrm{NH}_{3}\right)_{6}$. The parent peak has mass $193 \mathrm{u}$, the first evaporation peak of mass $176 \mathrm{u}$ corresponds to loss of one ammonia molecule, and the peak at $175 \mathrm{u}$ corresponds to a cluster that has lost another water molecule. The peak at $187 \mathrm{u}$ between the parent and first daughter peaks is a well understood instrumental artifact and can be disregarded.
Figure 4 summarizes the measured cluster species and their respective evaporation probabilities. Both the total amount of measured metastable evaporation and the branching ratios are given.

Figure 5 shows the total relative amount of metastable evaporation vs. cluster rank. The dots give the metastable evaporation probability of each individual cluster composition measured, and the large crosses are the average evaporation fraction within each rank, giving them equal weight. The lower left dashed line is a linear fit to the first four averages $(N=5-8)$ and the right dashed line has the same slope but is displaced in the ordinate to fit the averages for $N=9-11,16$.

The increasing trend in the evaporation rate with rank is a general phenomenon and is well understood as an effect of the increasing heat capacity with size (see, e.g., Ref. 31). In addition to the general increase, a clear jump occurs between the cluster sizes $N=8$ and 9 . This can be due to one or both of two reasons. Either the stability changes between $N=9$ and $N=8$, due to an increased stability of $N=8$ relative to $N=9$, related to a shell closing at the $N=8$ cluster or, alternatively, the shift can be caused by an increased heat capacity of the $N$ $\geq 9$ clusters compared to the $N \leq 8$ species.

We can estimate the effects of these two possible explanations in terms of changes in binding energy or in heat capacity, under the assumption that all clusters have evaporated at least one molecule after creation. In that case, the highest energy in the ensemble for clusters of size $N$ will be

$$
E_{\max , N}=\frac{E_{a, N} C_{v, N}}{\ln \left(\omega_{N} t_{N}\right)}+\frac{E_{a, N}}{2},
$$

where $E_{a, N}$ is the evaporative activation energy for loss of one molecule, $C_{v, N}$ is the heat capacity in units of Boltzmann's constant, and $\ln \left(\omega_{N} t_{N}\right) \equiv G$ is the Gspann parameter. ${ }^{34}$ We will set the evaporative activation energy equal to the dissociation energy (we find the likelihood for an activation barrier for the attachment negligible). Both the frequency factor $\omega$ and $t$ (time since creation) depend weakly on $N$. For $\omega$, we use $6.33 \cdot N^{2 / 3} \cdot 10^{16} \mathrm{~s}^{-1}$ which is the value calculated for water clusters with a microcanonical daughter temperature of $150 \mathrm{~K},{ }^{31}$ and $t$ is calculated using known instrumental dimensions and applied electric potentials. The amount of metastable evaporation during the flight time $t_{5}^{\prime}$ in the straight section of the apparatus is proportional to the change in maximum energy during this time. In terms of the evaporated fraction, $f_{N}$, and the intensity of the parent cluster, $I_{N}$, we have

$$
\begin{aligned}
I_{N} f_{N} \propto \Delta E & =E_{\max , N, t_{4}}-E_{\max , N, t_{5}} \\
& =E_{a, N} C_{v, N}\left(\frac{1}{\ln \left(\omega_{N} t_{N, 4}\right)}-\frac{1}{\ln \left(\omega_{N} t_{N, 5}\right)}\right) \\
& =E_{a, N} C_{v, N} \Delta G_{N}^{-1} .
\end{aligned}
$$

We can compare the experimental value of this for $N=8$ and $N$ $=9$ after the envelope function of the abundance distributions generated by the specific source conditions is removed from the data. This is done by dividing the experimental abundance spectra with a smooth function. The result is a fairly constant abundance distribution in the size interval $N=6-12$, but with 
rank (N)
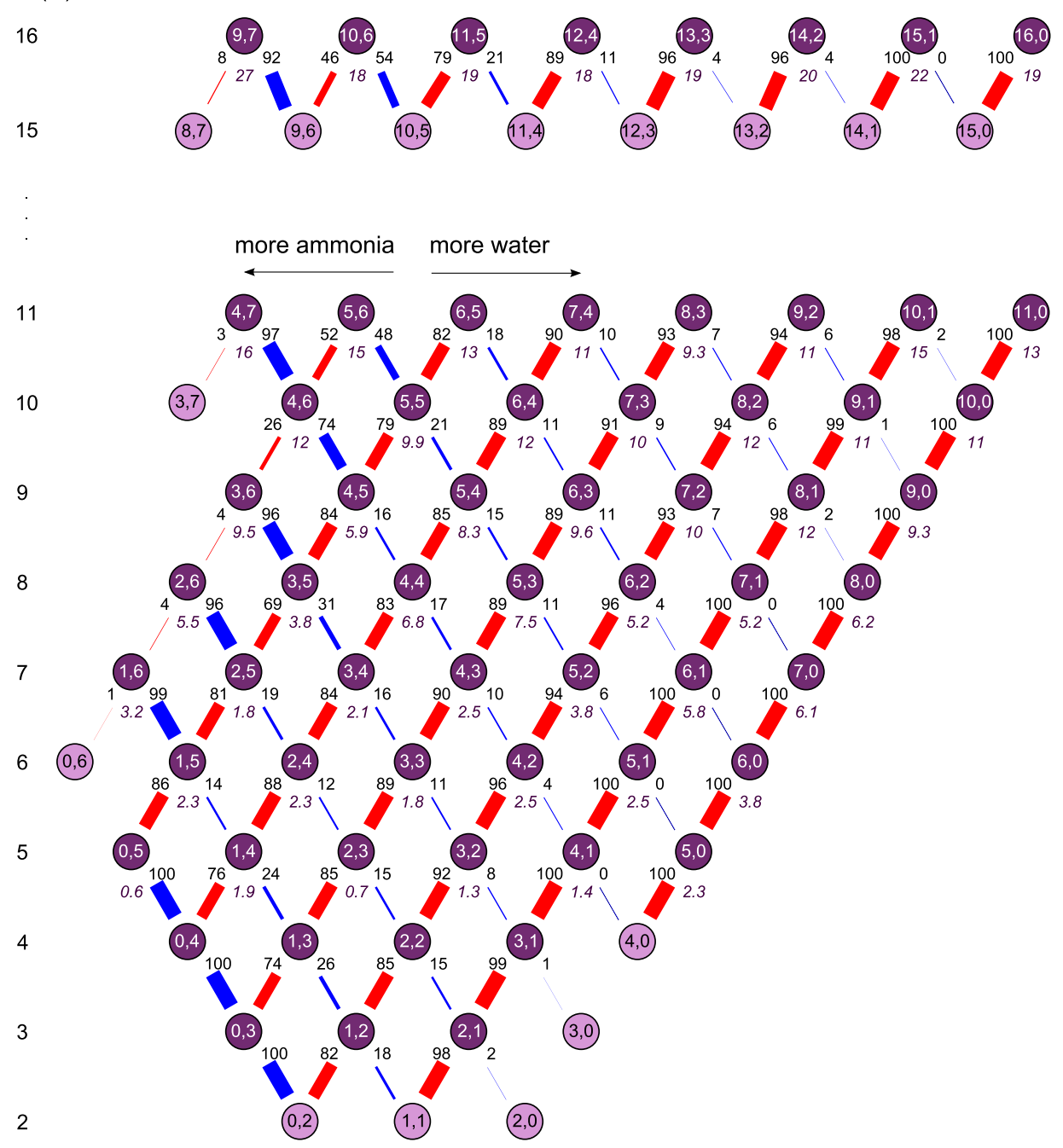

FIG. 4. Map of the measured metastable decays. Clusters are represented by dark colored circles. The few clusters for which metastable decay could not be measured are shown in lighter color. The number of water and ammonia molecules is given by the numbers $(n, m)$ in the circles. The widths of the bars from each cluster give the relative spontaneous evaporation fraction of water (pointing left, down) and ammonia (pointing right, down). The values of these branching ratios are given in percent next to the bars. The numbers in italic just below the circles represent the total evaporation in parts per thousand (\%o). The ranks, $N$, are given to the left of the diagram. For the smallest clusters, the amount of decay was too small for a reliable determination of the decay characteristics.

abundances, $I_{N}$, that are a factor of $\approx 0.9$ times lower at $N$ $=9$ compared with the $N=8$ clusters. With the fraction of evaporation probabilities from Fig. 5 being $f_{8} / f_{9}=0.6$, we get (with $\Delta G_{9} / \Delta G_{8} \approx 1$ ) that

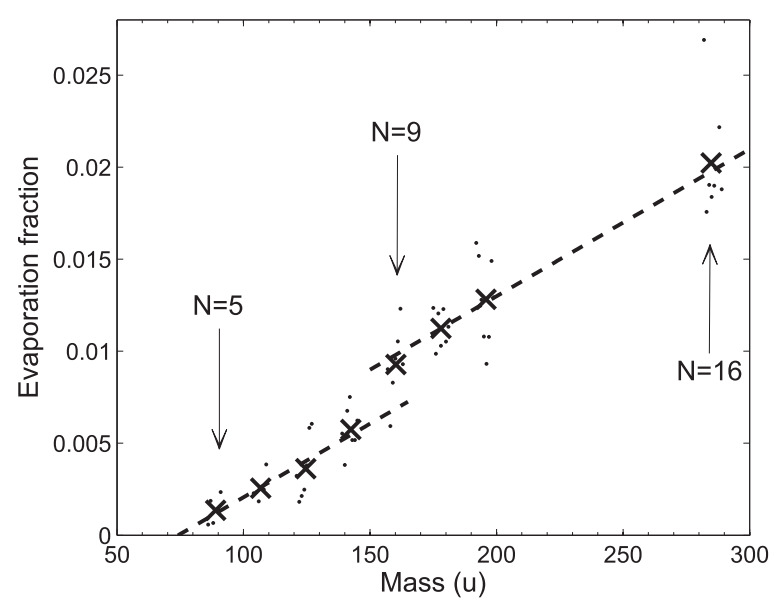

FIG. 5. Evaporation fraction for the measured clusters. Small dots represent specific cluster compositions and the large crosses the average values of these within each cluster rank, $N$. The two dashed lines have identical slope, fitted to the first four averages $(N=5-8)$.

$$
\frac{f_{8} I_{8}}{f_{9} I_{9}} \approx \frac{C_{v, 8} E_{a, 8}}{C_{v, 9} E_{a, 9}} \approx 0.7
$$

It is not possible to disentangle the effect of the two factors further in any rigorous way. We will tentatively suggest that the reason the ratio is less than unity is due to the higher heat capacities of the $N=9$ species because a significantly higher binding energy for $N=9$ clusters compared to $N=8$ species seems unlikely. It actually seems more likely that it is lower. A higher nonamer heat capacity, on the other hand, is consistent with the expectation that this species has smaller average intermolecular vibrational frequencies than the octamers. This makes the suppression of the vibrational excitation due to the quantized level structure less severe for these species. Judged by the slope and the jump of the two lines, the increase in heat capacity corresponds to two additional molecules added, an increase that persists when more molecules are added.

Another, even more striking, trend is that for $m \geq 6$, ammonia molecules are lost, whereas for $m<6$, the dominant loss channel is water molecules. This is illustrated in Fig. 6 which shows the fraction of water loss through spontaneous evaporation as a function of ammonia content in the cluster. Each frame in Fig. 6 shows water evaporation from clusters with a 


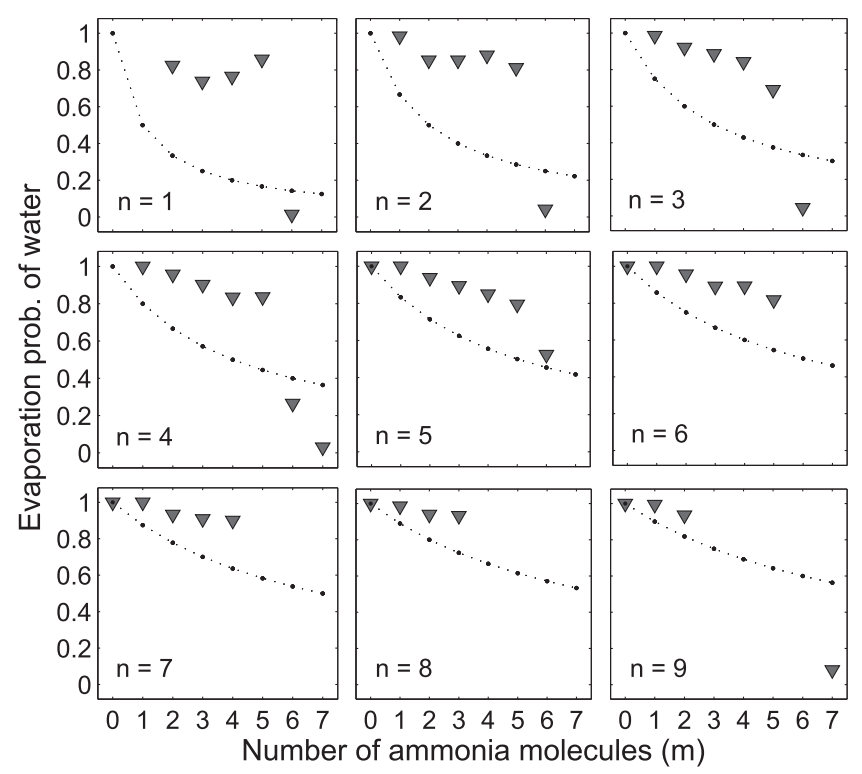

FIG. 6. The water evaporation fraction as a function of ammonia content $(\mathrm{m})$ in the clusters. In each frame, the number of water molecules $(n)$ is constant with the value indicated. The lines represent the probability that a lost molecule would be water if all molecules had identical probabilities of evaporation.

specific number of water molecules $(n=1,2, \ldots)$ with varying ammonia content. The lines represent the corresponding relative evaporation probabilities of a water molecule if the water and ammonia molecules behaved indistinguishably in the evaporation process. A sudden drop in water evaporation probability for clusters with six or more ammonia molecules is clearly visible. Figure 7 shows the complementary representation of the data where the number of ammonia molecules is kept constant in each frame and the ammonia evaporation probability is plotted. The onset of strong ammonia evaporation at $m \geq 6$ is clearly visible. The data in Fig. 7 for $n=4$, 5, 6 are similar to those measured in Ref. 30 and given in Fig. 3 of that paper. Some differences appear at $(n, m)$ $=(6,4-5)$, but overall, the agreement is good. Given that the fragmentation follows from different preparations of the

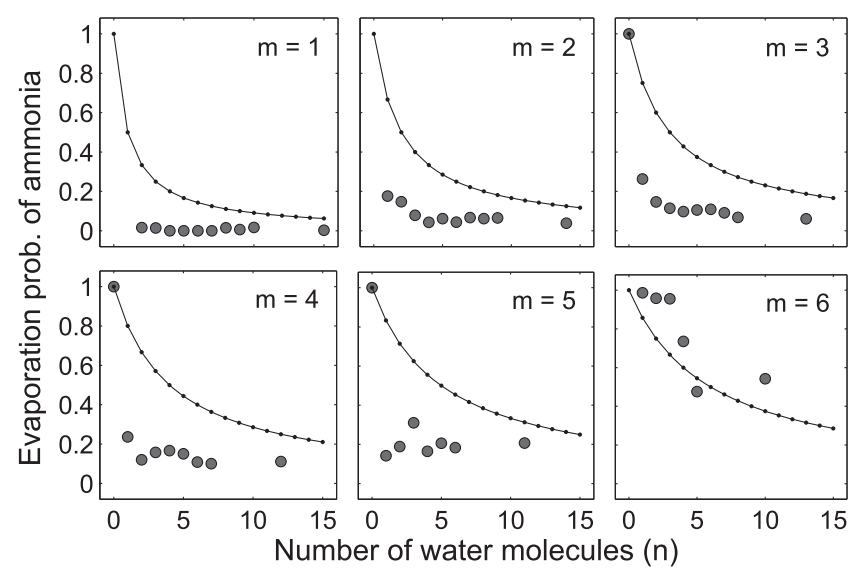

FIG. 7. Ammonia evaporation fractions as a function of water content $(n)$ in the clusters. In each frame, the number of ammonia molecules $(m)$ is kept constant at the value given. The lines are the probabilities of ammonia loss if water and ammonia molecules were indistinguishable in the evaporation process. clusters (spontaneous decay here vs. collisional induced dissociation), the agreement is rather good and corroborates the statistical decay ansatz underlying the analysis here and implicitly in Ref. 30. The close but not absolute agreement between branching ratios from spontaneous decays and CID-induced decay is similar to previous observations on silicon clusters. ${ }^{35}$ We expect that the spontaneous evaporation data here represent the most gentle probe of the two methods and will analyze the data as such.

\section{ANALYSIS AND DISCUSSION}

When both decay channels have measurable intensities, we can deduce free energy differences between the water and the ammonia evaporation channels. The ratio of water and ammonia loss, denoted $r$, is also the ratio between the rate constants for the two processes. We use the expression for the rate constants $k_{\text {decay }}$ from the theory of detailed balance $^{34}$

$$
k_{\text {decay }}=\frac{\sigma m}{\pi^{2} \hbar^{2}}\left(k_{B} T_{\mathrm{d}}\right)^{2} Z_{v, r, e l, n}\left(T_{\mathrm{d}}\right) \frac{\rho_{\text {daughter }}\left(E-E_{\mathrm{a}}\right)}{\rho_{\text {parent }}(E)},
$$

where $\sigma$ is the capture cross section of the inverse (attachment) process, $m$ is the mass of the evaporating fragment (in principle, the reduced mass), and $T_{\mathrm{d}}$ is the microcanonical temperature of the daughter cluster. The $Z_{v, r, e l, n}$ is the canonical partition function for the spectrum of vibrational, rotational, electronic, and nuclear degrees of freedom of the evaporating fragment. It must be evaluated at the product/daughter temperature. The $\rho$ 's are the level densities of the parent and daughter clusters, and $E_{\mathrm{a}}$ is the activation energy for evaporating the molecule, assumed equal to the dissociation energy, as mentioned. Equation (4) is calculated assuming that the energy in the degrees of freedom included into the prefraction canonical partition function is relatively small. It is mainly the rotational degrees of freedom that are excited at the temperatures relevant here, and the approximation should be good.

When dividing the rate constant for water evaporation with ammonia evaporation, some common factors will cancel. Assuming that the capture cross section for the two molecules is the same, we get the following expression;

$$
\begin{aligned}
r & =\frac{\# \text { counts water loss }}{\# \text { counts ammonia loss }}=\frac{k_{\text {decay, } \mathrm{H}_{2} \mathrm{O}}}{k_{\text {decay, } \mathrm{NH}_{3}}} \\
& =\frac{m_{\mathrm{H}_{2} \mathrm{O}}}{m_{\mathrm{NH}_{3}}} \frac{Z_{v, r, e l, n, \mathrm{H}_{2} \mathrm{O}}\left(T_{\mathrm{d}, \mathrm{H}_{2} \mathrm{O}}\right)}{Z_{v, r, e l, n, \mathrm{NH}_{3}}\left(T_{\mathrm{d}, \mathrm{NH}_{3}}\right)} \frac{\rho_{W}\left(E-E_{\mathrm{a}, \mathrm{W}}\right)}{\rho_{A}\left(E-E_{\mathrm{a}, \mathrm{A}}\right)} .
\end{aligned}
$$

$\rho_{\mathrm{d}}$ is the level density of the daughter cluster, where the subscript indicates which molecule is evaporated, $d=W($ ater $)$, $A\left(\right.$ mmonia), and $E_{a, d}$ is the activation energy for evaporating the molecule with label $d$.

With the low temperatures and the relatively high rotational quantum energies of the molecules involved, the quantum statistics effects in the rotational partition functions are significant. These effects and those associated with the other indices in the canonical partition functions in Eq. (5) are included in the calculation for the free water and ammonia 
molecules given in Refs. 36 and 37 by a direct summation. The tabulated values for water can be represented by a power law in the relevant temperature interval

$$
Z_{W} \equiv Z_{v, r, e l, n, \mathrm{H}_{2} \mathrm{O}}=0.1432\left(\frac{T}{\mathrm{~K}}\right)^{1.44}
$$

For ammonia, the function given in Ref. 37 can likewise be approximated by a power law

$$
Z_{A} \equiv Z_{v, r, e l, n, \mathrm{NH}_{3}}=0.05760\left(\frac{T}{\mathrm{~K}}\right)^{1.83} .
$$

Both of these expressions take into account the decrease of the nuclear spin degrees of freedom of the cluster upon evaporation and can therefore be used directly in the rate constants. For later use, we define the dimensionless function $Q$ as

$$
Q \equiv \frac{m_{\mathrm{NH}_{3}} Z_{A}}{m_{\mathrm{H}_{2} \mathrm{O}} Z_{W}} .
$$

As indicated, we must use the product (daughter) temperature for both the rotational-nuclear canonical partition function and for the translational factor $T^{2}$, keeping in mind that the two product temperatures are in general different. We have

$$
\frac{\rho_{W}\left(E-E_{\mathrm{a}, \mathrm{W}}\right)}{\rho_{A}\left(E-E_{\mathrm{a}, \mathrm{A}}\right)}=Q r=0.380 r \frac{\left(T_{A} / \mathrm{K}\right)^{1.83}}{\left(T_{W} / \mathrm{K}\right)^{1.44}} .
$$

We will now interpret the ratio of level densities. Naively, it is the exponential of the difference in the entropy of the two products, but this simple estimate ignores the fact that the level densities are evaluated at different energies. It is possible to understand this difference if one takes the detour over canonical quantities. This is accomplished with the use of the expression for the level densities ${ }^{38}$

$$
\rho(E)=\left(2 \pi C T^{2}\right)^{-1 / 2} Z e^{\beta E},
$$

where $C$ is the heat capacity, and the temperature is determined as $^{38}$

$$
\bar{E}(T)=E+k_{B} T,
$$

with $E$ the excitation energy, $\bar{E}$ the corresponding canonical energy, and $T$ the microcanonical temperature. Equation (10) has been shown numerically to be a very good approximation. ${ }^{39}$ Denoting the microcanonical temperature of evaporation products by $T_{d}$, we can then write the ratio of level densities as

$$
Q r=\frac{\rho_{W}\left(E-E_{\mathrm{a}, \mathrm{W}}\right)}{\rho_{A}\left(E-E_{\mathrm{a}, \mathrm{A}}\right)}=\left(\frac{C_{A}}{C_{W}}\right)^{1 / 2} \frac{T_{A}}{T_{W}} e^{S_{W}\left(T_{W}\right)-S_{A}\left(T_{A}\right)} .
$$

We expand the entropies around the parent temperature, $T_{0}$, to get

$$
\begin{aligned}
S_{W}\left(T_{W}\right)-S_{A}\left(T_{A}\right) \approx & S_{W}\left(T_{0}\right)-S_{A}\left(T_{0}\right)+C_{A}-C_{W} \\
& +T_{0}^{-1}\left(T_{W} C_{W}-T_{A} C_{A}\right) .
\end{aligned}
$$

The next order terms in the expansion are $-C_{d}\left(T_{d}-T_{0}\right)^{2} / 2 T_{0}^{2}$, ignoring the possible temperature dependence of the heat capacity. The difference of these two second order terms is

$$
\begin{gathered}
-\frac{1}{2} \frac{C_{W}}{T_{0}^{2}}\left(T_{W}-T_{0}\right)^{2}+\frac{1}{2} \frac{C_{A}}{T_{0}^{2}}\left(T_{A}-T_{0}\right)^{2} \\
=-\frac{1}{2} \frac{C_{W}}{T_{0}^{2}}\left(\frac{E_{a, W}}{C_{W}}\right)^{2}+\frac{1}{2} \frac{C_{A}}{T_{0}^{2}}\left(\frac{E_{a, A}}{C_{A}}\right)^{2},
\end{gathered}
$$

where the equality follows from the definition of the heat capacity. We can reduce this by expressing the initial temperature in terms of the activation energies, $E_{a}$, the unimolecular reaction frequency factor, $\omega$, and the heat capacity $C$. For a reaction with no competing channels, the result is

$$
T_{0} \approx E_{a}\left(\frac{1}{G}+\frac{1}{2 C}\right) .
$$

The last term on the right hand side is the leading order finite heat bath correction. The frequency factor needs a correction when there are two competing channels, but this will be on the order of a factor two, which is a minor modification. Applying Eq. (15) to the two terms in Eq. (14) separately, the difference can then be expressed as

$$
\frac{1}{2} \frac{C_{W}}{\left(\frac{C_{W}}{G}+\frac{1}{2}\right)^{2}}-\frac{1}{2} \frac{C_{A}}{\left(\frac{C_{A}}{G}+\frac{1}{2}\right)^{2}} .
$$

When judged by the measured heat capacities of both protonated and deprotonated water clusters, ${ }^{31}$ which showed an additional heat capacity around 6 (in units of $k_{B}$ ) per added molecule, the denominators exceed unity for fairly small cluster sizes. Given that the two heat capacities $C_{W}$ and $C_{A}$ refer to clusters that only differ by the substitution of one water with one ammonia molecule, and that intra-molecular vibrations are unlikely to be excited at the relevant temperatures, it is most likely that these two heat capacities are very similar, specifically that the difference is on the order of unity or even less. In summary, the second and higher order terms in the expansion are not expected to contribute significantly and will be ignored in the following.

We can rewrite Eq. (13) if we express the product temperatures in terms of the parent microcanonical temperature $T_{0}$. The relation between the two temperatures is

$$
T_{A} \approx T_{0}-\frac{E_{a, A}}{C_{A}}
$$

and similarly for $T_{W}$, with subscripts $A$ replaced by $W$. Inserting this gives

$$
Q r \approx\left(\frac{C_{A}}{C_{W}}\right)^{1 / 2} \frac{T_{A}}{T_{W}} \exp \left(\frac{\Delta F_{A}-\Delta F_{W}}{T_{0}}\right),
$$

where the Helmholtz free energies of evaporation $\Delta F_{W}, \Delta F_{A}$ are defined as

$$
\Delta F_{A} \equiv E_{a, A}-T_{0} S_{A}\left(T_{0}\right)
$$

and similarly for the water loss. As argued above, we expect that the ratio $C_{A} / C_{W}$ is close to unity, and we will continue with the simplification $C_{A} / C_{W}=1$. We then have

$$
\begin{aligned}
\Delta F_{A}-\Delta F_{W} & \approx T_{0}\left(\ln \left(Q r \frac{T_{W}}{T_{A}}\right)\right) \\
& =T_{0}\left(\ln \left(r \frac{m_{\mathrm{NH}_{3}} Z_{A}}{m_{\mathrm{H}_{2} \mathrm{O}} Z_{W}} \frac{T_{W}}{T_{A}}\right)\right) .
\end{aligned}
$$


The fraction of temperatures will partly cancel the temperature dependence of $Q$. We have

$$
\Delta F_{A}-\Delta F_{W} \approx T_{0} \ln \left(0.380 r \frac{\left(T_{A} / \mathrm{K}\right)^{0.83}}{\left(T_{W} / \mathrm{K}\right)^{0.44}}\right) .
$$

The temperatures that appear here are not trivially determined. Fortunately, the result is not very sensitive to their precise values. As an example, consider the difference between the logarithm of the two sets of values of $\left(T_{A}, T_{W}\right)=(200$, 150) $\mathrm{K}$ and $\left(T_{A}, T_{W}\right)=(150,200) \mathrm{K}$. The logarithm of these values differs only by 0.38 . It should be kept in mind that the two temperatures refer to clusters that originate from the same precursor and have similar unimolecular rate constants. Large differences in their temperature are therefore highly unlikely. We can therefore summarily set the two values of the temperatures equal to the same value. We will use the set $T_{0}=T_{A}=T_{W}=150 \mathrm{~K}$ for all cluster sizes and compositions.

Figure 8 shows the free energy differences calculated from data and Eq. (21) as a function of the ammonia content, with each trace representing a definite water content, excluding clusters without water or ammonia. These evaporative free energy differences are also the Helmholtz free energy differences of the product clusters. For the decay of the cluster composed of $(n, m)$ water and ammonia molecules, it is

$$
\Delta F_{A}-\Delta F_{W}=F_{n, m-1}-F_{n-1, m},
$$

where the subscripts give the composition of the cluster. As derived, these free energies refer to identical temperatures for the two products. The approximate scaling for $m \leq 5$ means that in that range, this difference is independent of $n$,

$$
F_{n, m-1}-F_{n-1, m} \approx F_{m-1}-F_{m}, \quad(m \leq 5, \text { same rank }) .
$$

It is not possible to draw conclusions on the energies and entropies separately based on this result, and we will refrain from making conjectures.

The scaling of the curves for different water content in Fig. (8) is striking. The only deviation from good scaling

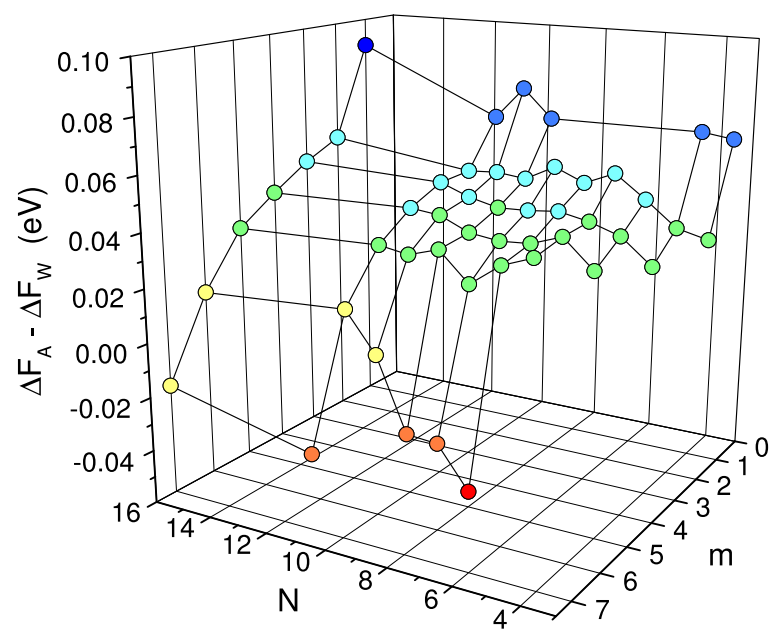

FIG. 8. The evaporative free energy difference for loss of an ammonia and a water molecule. Lines connect clusters with identical water contents and ranks. appears at $m=6$. The inset in the figure shows that the observed deviations for this class of clusters correlate strongly with the water content.

We interpret this scaling as an evidence for a cluster structure where four ammonia molecules are tightly bound to a central ammonium ion. Additional molecules outside this inner shell and water molecules filling the shell in place of ammonia molecules for the less ammonia-containing clusters are less tightly bound. The change in free energy differences between the $m=1$ and the $m=2$ clusters is remarkable because the value drops by only ca. $0.04 \mathrm{eV}$. This is a factor of 40 less than the difference in proton affinity between water and ammonia. Ammonia has a stronger proton affinity than water, $853.6 \mathrm{~kJ} / \mathrm{mol}$ vs. $691 \mathrm{~kJ} / \mathrm{mol},{ }^{24}$ i.e., a difference of $1.7 \mathrm{eV}$. A similar reduction is found if the dissociation of a protonated ammonia-water complex is considered, according to the quantum chemical calculations in Ref. 20. The stabilizing effect of the much higher proton affinity for ammonia clusters is therefore strongly reduced, compared to any simple consideration based on the single molecule proton affinity. However, the observed drop between the $m=1$ and the $m=2$ clusters is, although not without scatter, not strongly dependent on the water content. This points to a protonation effect which is still fairly localized. The data points for $m=1$ include points for $n=2$ to $n=6$. This suggests that the stable water species formed on loss of ammonia has a Zundel core structure (the two outliers in the plot are not for the clusters with $n=1,2)$.

The almost constant free energy difference for the next four ammonia molecules added suggests that the binding energies of the ammonia to the ammonium ion is close to linear, i.e., independent of the total number of ammonia bound to the ammonium. The plateau energy of $0.04 \mathrm{eV}$ is the difference between the bond energy of an ammonia and a water molecule to the ammonium ion, less the water-water interaction energy. The existence of the $m=2-5$ plateau strongly supports the hypothesis of a shell of four ammonia molecules surrounding the ammonium ion.

At $m=6$, the free energy differences disperse with the number of water molecules. The inset in Fig. 8 shows this as a function of $n$. There is a clear tendency for the value to grow with the number of water molecules in the cluster. This can be ascribed to the fact that the free energy increases with decreasing concentration. A fit with the expected logarithmic dependence gives a temperature which is twice the value of $T_{0}$ and an offset corresponding to the free energy difference of $-0.04 \mathrm{eV}$ for the cluster with a single water and a single ammonia molecule outside the closed shell. Although the fitted temperature is of the correct order of magnitude, the value still differs significantly from the expected $T_{0}$. There can be several possible reasons for this discrepancy. A qualified discussion of this will require more detailed experimental results and must await these. Here we will just note the more robust fit of the offset energy of $-0.04 \mathrm{eV}$. This indicates that ammonia evaporates more freely than water from mixed clusters for equal concentrations.

A comparison of the free energies found here with those of Ref. 30 is possible for the theoretically calculated series for 1,2 , and 3 water molecules. The free energies in that work 
are the Gibbs free energies, but as the number of molecules in the two decay channels is identical, the $P V$ term cancels in the difference and the calculations can be compared directly with the Helmholtz free energies derived here. The trends in the two data sets are similar, although the theoretical calculation shows more variation in the differences in the plateau between $m=2$ and $m=5$ than do the strikingly constant experimental results here. The overall magnitude of the difference is also predicted somewhat too large. Discussing these differences, it is important to keep in mind that the data are recorded at elevated excitation energies where thermal effects associated with anharmonicities, not accounted for in the quantum chemical calculation, may be present.

\section{SUMMARY}

The spontaneous metastable decays in free flight of small, mixed, and protonated ammonia-water clusters produced in a corona discharge source have been measured. Generally the metastable decay fraction increases with cluster size. Loss of ammonia and water molecules competes with branching ratios that depend on cluster composition. Evaporative free energy differences for competing water-ammonia loss channels were calculated from the measured branching ratios. They are on the order of several tens of $\mathrm{meV}$, and show a very strong degree of scaling, with the differences between the free energies of the products of water and ammonia loss almost independent of the water content up to an ammonia content of five molecules. This strongly suggests that a stable core of ammonia molecules exists for clusters with an ammonia content up to five molecules, after which water is the more strongly bound molecule.

\section{SUPPLEMENTARY MATERIAL}

See supplementary material for the data plotted in Fig. 8.

\section{ACKNOWLEDGMENTS}

This work has been supported by the ITS-LEIF Project No. P09094E, the Gothenburg Nanoparticles Platform, and the Swedish science research foundation VR.

${ }^{1}$ M. Kulmala, H. Vehkamäki, T. Vesala, J. C. Barrett, and C. F. Clement, J. Aerosol Sci. 26, 547-558 (1995).

${ }^{2}$ J. Kirkby, J. Curtius, J. Almeida, E. Dunne, J. Duplissy, S. Ehrhart, A. Franchin, S. Gagné, L. Ickes, A. Kürten, A. Kupc, A. Metzger, F. Riccobono, L. Rondo, S. Schobesberger, G. Tsagkogeorgas, D. Wimmer, A. Amorim, F. Bianchi, M. Breitenlechner, A. David, J. Dommen, A. Downard, M. Ehn, R. C. Flagan, S. Haider, A. Hansel, D. Hauser, W. Jud, H. Junninen, F. Kreissl, A. Kvashin, A. Laaksonen, K. Lehtipalo, J. Lima, E. R. Lovejoy, V. Makhmutov, S. Mathot, J. Mikkilä, P. Minginette, S. Mogo, T. Nieminen, A. Onnela, P. Pereira, T. Petäjä, R. Schnitzhofer, J. H. Seinfeld, M. Sipilä, Y. Stozhkov, F. Stratmann, A. Tomé, J. Vanhanen, Y. Viisanen, A. Virtala, P. E. Wagner, H. Walther, E. Weingartner, H. Wex, P. M. Winkler, K. S. Carslaw, D. R. Worsnop, U. Baltensperger, and M. Kulmala, Nature 476, 429 (2011).

${ }^{3}$ E. M. Dunne, H. Gordon, A. Kürten, J. Almeida, J. Duplissy, C. Williamson, I. K. Ortega, K. J. Pringle, A. Adamov, U. Baltensperger, P. Barmet, F. Benduhn, F. Bianchi, M. Breitenlechner, A. Clarke, J. Curtius, J. Dommen, N. M. Donahue, S. Ehrhart, R. C. Flagan, A. Franchin, R. Guida, J. Hakala, A. Hansel, M. Heinritzi, T. Jokinen, J. Kangasluoma, J. Kirkby, M. Kulmala, A. Kupc, M. J. Lawler, K. Lehtipalo, V. Makhmutov, G. Mann, S. Mathot, J. Merikanto, P. Miettinen, A. Nenes, A. Onnela, A. Rap, C. L. S.
Reddington, F. Riccobono, N. A. D. Richards, A. D. Nigel, M. P. Rissanen, L. Rondo, N. Sarnela, S. Schobesberger, K. Sengupta, M. Simon, M. Sipilä, J. N. Smith, Y. Stozkhov, A. Tome, J. Trostl, P. E. Wagner, D. Wimmer, P. M. Winkler, D. R. Worsnop, and K. S. Carslaw, Science 354, 1119-1124 (2016).

${ }^{4}$ M. Kulmala, J. Kontkanen, H. Junninen, K. Lehtipalo, H. E. Manninen, T. Nieminen, T. Petäjä, M. Sipilä, S. Schobesberger, P. Rantala, A. Franchin, T. Jokinen, E. Järvinen, M. äijälä, J. Kangasluoma, J. Hakala, P. P. Aalto, P. Paasonen, J. Mikkilä, J. Vanhanen, J. Aalto, H. Hakola, U. Makkonen, T. Ruuskanen, R. L. Mauldin III, J. Duplissy, H. Vehkamäki, J. Bäck, A. Kortelainen, I. Riipinen, T. Kurtén, M. V. Johnston, J. N. Smith, M. Ehn,

T. F. Mentel, K. E. J. Lehtinen, A. Laaksonen, V.-M. Kerminen, and D. R. Worsnop, Science 339, 943 (2013).

${ }^{5}$ T. Kurtén, V. Loukonen, H. Vehkamäki, and M. Kulmala, Atmos. Chem. Phys. 8, 4095-4103 (2008).

${ }^{6}$ S.-K. Miao, S. Jiang, X.-Q. Peng, Y.-R. Liu, Y.-J. Feng, Y.-B. Wang, F. Zhao, T. Huang, and W. Huang, RSC Adv. 8, 3250 (2018).

${ }^{7}$ J. Almeida, S. Schobesberger, A. Kürten, I. K. Ortega, O. Kupiainen-Määttä, A. P. Praplan, A. Adamov, A. Amorim, F. Bianchi, M. Breitenlechner, A. David, J. Dommen, N. M. Donahue, A. Downard, E. Dunne, J. Duplissy, S. Ehrhart, R. C. Flagan, A. Franchin, R. Guida, J. Hakala, A. Hansel, M. Heinritzi, H. Henschel, T. Jokinen, H. Junninen, M. Kajos, J. Kangasluoma, H. Keskinen, A. Kupc, T. Kurtén, A. N. Kvashin, A. Laaksonen, K. Lehtipalo, M. Leiminger, J. Leppä, V. Loukonen, V. Makhmutov, S. Mathot, M. J. McGrath, T. Nieminen, T. Olenius, A. Onnela, T. Petäjä, F. Riccobono, I. Riipinen, M. Rissanen, L. Rondo, T. Ruuskanen, F. D. Santos, N. Sarnela, S. Schallhart, R. Schnitzhofer, J. H. Seinfeld, M. Simon, M. Sipilä, Y. Stozhkov, F. Stratmann, A. Tomé, J. Tröstl, G. Tsagkogeorgas, P. Vaattovaara, Y. Viisanen, A. Virtanen, A. Vrtala, P. E. Wagner, E. Weingartner, H. Wex, C. Williamson, D. Wimmer, P. Ye, T. Yli-Juuti, K. S. Carslaw, M. Kulmala, J. Curtius, U. Baltensperger, D. R. Worsnop, H. Vehkamäki, and J. Kirkby, Nature 502, 359-363 (2013).

${ }^{8}$ J. Elm, M. Passananti, T. Kurtén, and H. Vehkamäki, J. Phys. Chem. A 121, 6155-6164 (2017).

${ }^{9}$ J. Elm, J. Phys. Chem. A 121, 8288-8295 (2017).

${ }^{10}$ J. Julin, B. N. Murphy, D. Patoulias, C. Fountoukis, T. Olenius, S. N. Pandis, and I. Riipinen, Environ. Sci. Technol. 52, 692-700 (2018).

${ }^{11}$ H. Svensmark and E. Friis-Christensen, J. Atmos. Sol.-Terr. Phys. 59, 1225-1232 (1997).

${ }^{12}$ F. Q. Yu and R. P. Turco, J. Geophys. Res.: Atmos. 106, 4797, https://doi.org/10.1029/2000jd900539 (2001).

${ }^{13}$ M. B. Enghoff, J. O. P. Pedersen, U. I. Uggerhøj, S. M. Paling, and H. Svensmark, Geophys. Res. Lett. 38, L09805, https://doi.org/10.1029/ $2011 \mathrm{gl047036}$ (2011).

${ }^{14}$ J. M. Price, M. W. Crofton, and Y. T. Lee, J. Phys. Chem. 95, 2182-2195 (1991)

${ }^{15}$ J.-W. Shin, N. I. Hammer, E. G. Diken, M. A. Johnson, R. S. Walters, T. D. Jaeger, M. A. Duncan, R. A. Christie, and K. D. Jordan, Science 304, 1137 (2004)

${ }^{16}$ Y.-S. Wang, H.-C. Chang, J.-C. Jiang, S. H. Lin, Y. T. Lee, and H.-C. Chang, J. Am. Chem. Soc. 120, 8777 (1998).

${ }^{17}$ J. C. Jiang, H.-C. Chang, Y. T. Lee, and S. H. Lin, J. Phys. Chem. A 103, 3123 (1999)

${ }^{18}$ C. A. Deakyne, J. Phys. Chem. 90, 6625 (1986).

${ }^{19}$ M. Meot-Ner (Mautner), Chem. Rev. 105, 213 (2005).

${ }^{20}$ H. H. Bueker and E. Uggerud, J. Phys. Chem. 99, 5945 (1995).

${ }^{21}$ F. Brugé, M. Bernasconi, and M. Parrinello, J. Chem. Phys. 110, 4734 (1999).

${ }^{22}$ S. Karthikeyan, J. N. Singh, M. Park, R. Kumar, and K. S. Kim, J. Chem. Phys. 128, 244304 (2008).

${ }^{23}$ J. Douday, F. Calvo, and F. Spiegelman, J. Chem. Phys. 129, 154305 (2008).

${ }^{24}$ E. P. L. Hunter and S. G. Lias, J. Phys. Chem. Ref. Data 27, 413-656 (1998).

${ }^{25}$ J. D. Payzant, A. J. Cunningham, and P. Kebarle, Can. J. Chem. 51, 3242 (1973).

${ }^{26}$ K. Y. Choo, H. Shinohara, and N. Nishi, Chem. Phys. Lett. 95(3), 102 (1983).

${ }^{27}$ H. Shinohara, U. Nagashima, and N. Nishi, Chem. Phys. Lett. 111(4-5), 511 (1984).

${ }^{28}$ H. Shinohara, U. Nagashima, H. Tanaka, and N. Nishi, J. Chem. Phys. 83(8), 4183 (1985).

${ }^{29}$ H. Shinohara, N. Nishi, and N. Washida, Chem. Phys. Lett. 153(5), 417 (1988).

${ }^{30}$ P. Hvelplund, T. Kurtén, K. Støchkel, M. J. Ryding, S. Brøndsted Nielsen, and E. Uggerud, J. Phys. Chem. A 114, 7301-7310 (2010). 
${ }^{31}$ A. E. K. Sundén, K. Støchkel, S. Panja, U. Kadhane, P. Hvelplund, S. Brøndsted Nielsen, H. Zettergren, B. Dynefors, and K. Hansen, J. Chem. Phys. 130, 224308 (2009).

${ }^{32}$ P. U. Andersson, M. J. Ryding, O. Sekiguchi, and E. Uggerud, Phys. Chem. Chem. Phys. 10, 6127 (2008).

${ }^{33}$ K. Hansen, P. U. Andersson, and E. Uggerud, J. Chem. Phys. 131, 124303 (2009).

${ }^{34}$ K. Hansen and U. Näher, Phys. Rev. A 60, 1240 (1999).
${ }^{35}$ P. Ferrari, E. Janssens, P. Lievens, and K. Hansen, J. Chem. Phys. 143, 224313 (2015).

${ }^{36}$ M. Vidler and J. Tennyson, J. Chem. Phys. 113, 9766 (2000).

${ }^{37}$ C. Sousa-Silva, N. Hesketh, S. N. Yurchenko, C. Hill, and J. Tennyson, J. Quant. Spectrosc. Radiat. Transfer 142, 66-74 (2014).

${ }^{38}$ J. U. Andersen, E. Bonderup, and K. Hansen, J. Chem. Phys. 114, 6518 (2001).

${ }^{39}$ K. Hansen, J. Chem. Phys. 128, 194103 (2008). 